http://jmscr.igmpublication.org/home/ ISSN (e)-2347-176x ISSN (p) 2455-0450 crossref DOI: https://dx.doi.org/10.18535/jmscr/v8i5.04

\title{
Comparison of the effectiveness of Glycerine Magnesium Sulphate paste vs Heparinoid (Thrombophob) ointment on phlebitis among patients on peripheral intravenous therapy
}

\section{Authors \\ Shaly Selva Grace ${ }^{1 *}$, Mrs. Florence Segaran², Mrs. Jeyalindha Christopher ${ }^{3}$, Dr Inian Samarasam ${ }^{4}$}

${ }^{1}$ Nursing Student II year M.Sc. Nursing, College of Nursing, Christian Medical College, Vellore, Tamil Nadu, India

${ }^{2}$ Professor, Deputy Nursing Superintendent and Head of Operation theatre Nursing, Christian Medical College,

Vellore, Tamil Nadu, India

${ }^{3}$ Professor, Head of Accidents and Emergency Nursing, Christian Medical College, Vellore, Tamil Nadu, India

${ }^{4}$ Professor and Head of Upper GI Surgery Unit, Department of Surgery-Unit -III, Christian Medical College, Vellore *Corresponding Author

Shaly Selva Grace. E

\begin{abstract}
Aim: The aim of this study was to compare the effectiveness of Glycerine Magnesium Sulphate paste vs Heparinoid (Thrombophob) Ointment on Phlebitis among patients on peripheral intravenous therapy.

Background: Pain being the fifth vital sign should not be underestimated. Phlebitis causes pain, and discomfort to patients seeking medical help. Various treatment modalities are available for treating phlebitis.

Design: Quantitative approach, an experimental study with pre-test and post-test design

Methodology: The study was conducted in the general surgical and orthopaedic wards among 110 patients. Block randomization method was used. The subjects were randomly allocated to control and experimental group using Sequentially Numbered, Opaque Sealed envelopes (SNOSE) method. Subjects were observed for 48 hours with an interval of 24 hours. Visual infusion phlebitis scale and numeric pain intensity scale were used to collect data.

Results: Result showed that Glycerine Magnesium Sulphate paste was more effective than Heparinoid (Thrombophob) Ointment application based on the observation at 24 hours ( $p<0.0001$ ). The Mean reduction rates in phlebitis at the baseline reading, at 24 hours and at 48 hours is 2.95, 2.67 and 1.78 in the control group and 3.07, 1.51 and 0.55 in the experimental group. Both interventions were found to be effective at 48 hours of the observation.

Conclusion: This study demonstrated evidence on the more effective intervention (Glycerine Magnesium Sulphate paste) for the management of phlebitis.

Trial Registration: The study was registered in Clinical Trials Registry of India (CTRI/2018/05/013888).

Keywords: Pain, Peripheral Intravenous therapy, Phlebitis.
\end{abstract}




\section{Introduction}

Intravenous therapy aims to administer medications at regular intervals that patients receive on a daily basis and it is one of the most common procedures performed in the hospital around the globe ${ }^{17}$. For any patient who require medical or surgical management to treat promptly and to achieve a better outcome, intravenous cannulation is done on the day of admission. However, the intravenous therapy can be associated with several potential complications that are categorized as local or systemic ${ }^{17}$. Local complications include Phlebitis, Infiltration, Extravasation, Haemorrhage and Local Infections. Systemic complications include Pulmonary oedema, Air embolism, Catheter embolism and Catheter related bloodstream. The most common complication associated with this procedure is phlebitis with incidence varying in different settings from $3.7 \%$ to $67.24 \%{ }^{17}$. The increasing rate of complications is likely due to absence of standard protocol in vein puncture and need for immediate interventions, which can affect the quality of catheterizations and its subsequent care $^{8}$.

A significant number of factors have been included in the origin of phlebitis according to Mestre. According to They can be Ferrite advanced age, the female gender, the Caucasian group, and certain underlying processes, such as the hypoalbuminemia or neutropenia are at a higher risk to develop phlebitis. The key factors causing phlebitis are catheter material, the extent of the catheter's lumen (larger catheters have a greater risk than smaller catheters), low $\mathrm{pH}$, potassium chloride, hypertonic solutions, amino acids and some antibiotics ${ }^{3}$.

Different treatments are available for phlebitis, which includes application of moist warm compress or cold compress to the affected site, discontinuing intravenous catheter and restarting it in another site (CDC 2011), in addition to the administration of analgesics Smelter stated that local topical application of Heparinoid (Thrombophob) ointment and application of
Ichthammol glycerine are used. In few other hospitals Glycerine Magnesium Sulphate paste is also used.

\section{Significance of the study}

Approximately 20 million out of 40 million patients hospitalized in the United States have been reported to have received intravenous therapy as stated by yalcin. Phlebitis is a problem of concern which is usually developed during hospitalization. Phlebitis and its complications are potentially harmful sources for systemic infections and with the presence of phlebitis or when left untreated the risk of developing systemic infections increases by 18 times. Though various interventions such as removal of the IV catheter, warm compress, cold applications, application of Ichthammol glycerine, Heparinoid (Thrombophob) ointment are available to treat phlebitis, patients prefer treatment which relieves phlebitis early at ease. Clinical observations and prior research findings in this area are inadequate. Judgment in deciding on the treatment modality is influenced by good clinical effect with minimal or no side-effects, the time taken for the reduction of phlebitis, cost effective and ease of availability.

Judgment in deciding on the treatment modality is influenced by good clinical effect with minimal or no side-effects, the time taken for the reduction of phlebitis, cost effective and ease of availability.

Giving the demand for inquiry on this issue and its importance as an indicator of the quality of nursing care, the goal of this work is to compare the effectiveness of topical Glycerine Magnesium Sulphate paste and Heparinoid (Thrombophob) ointment application in reducing phlebitis and pain in hospitalized adults. And suggests the most cost effective, less time consuming and easily available treatment measure with less or no sideeffects for the management of phlebitis.

\section{Statement of the Problem}

An experimental study to compare the effectiveness of topical Glycerine Magnesium Sulphate paste and Heparinoid (Thrombophob) ointment on phlebitis among patients on 
peripheral intravenous therapy in Christian Medical College, Vellore.

\section{Objectives}

1. To assess the effectiveness of Heparinoid (Thrombophob) ointment application on reduction in phlebitis.

2. To assess the effectiveness of Glycerine Magnesium Sulphate paste application on reduction in phlebitis.

3. To compare the effectiveness of Glycerine Magnesium Sulphate paste and Heparinoid (Thrombophob) ointment.

\section{Research Design}

Quantitative approach, an experimental study with pre-test and post-test design

\section{Setting of the study}

General surgical, orthopedics wards and 24 hours Injection room, Christian Medical College and Hospital, Vellore.

\section{Population}

Adult patients admitted in general surgical, orthopedic wards and 24 hours Injection room, and developed phlebitis as the result of intravenous therapy.110 IV patients (Group I: 55 \& Group II: 55).

\section{Sample}

Hundred and ten patients who developed phlebitis as the result of intravenous therapy during the data collection period and fulfilled the inclusion criteria. Both Glycerine Magnesium Sulphate paste group and Heparinoid (Thrombophob) Ointment application group had 55 subjects each.

\section{Criteria for sample selection}

Inclusion criteria

1. Patients who developed phlebitis only in the upper limb with visual infusion phlebitis score of two or more.

2. Patients who are 18 to 65 years old.

3. Patients with infusion related phlebitis and not received any form of intervention by staff nurse.

4. Patients who can speak Tamil, English, Hindi, Bengali and Telugu.

\section{Exclusion criteria}

1. Patients who are allergic to Glycerine Magnesium Sulphate paste or Heparinoid (Thrombophob) ointment.

2. Patients on central venous catheter on the same side of the limb, dermatological disorder, cardiac problems, lymphatic obstruction, Haematological disorders and bleeding disorders

3. Patients on intravenous chemotherapy.

4. Patients with injury on the same side of the limb.

\section{Sampling technique}

Consecutive sampling technique.

\section{Data collection instrument}

Questionnaire and observation methods were used to collect the data regarding the effective management measure for phlebitis and pain. The tool consists of the following items.

Part I: Demographic and clinical profile

Part II: Visual infusion phlebitis (V.I.P) scale

Part III: Numeric Pain Rating Scale (NPRS)

\section{Data collection procedure:}

The data was collected from the selected general surgical and orthopaedic wards for a time period of six weeks. Block randomization was done. The sequence of allocation was predetermined before enrolment. Sequentially Numbered, Opaque Sealed envelopes (SNOSE) given by the statistician was used. As each participant enters the study, he or she receives the next envelope in the sequence which will be opened by the staff nurse who is assigned to that subject. It is a single-blinded study. Patients who develop phlebitis during study period were identified and the interventions were provided by the investigator. The application was done 2 times a day. Subjects were observed for 48 hours with an interval of 24 hours

Data Analysis: Descriptive and Inferential statistics was applied. All the analyses were done using Statistical Package for Social Services (SPSS) software Version 21.0 (Armonk, NY: IBM Corp). 


\section{Ethical Consideration}

$>$ Institutional Review Board (Research

Committee, Ethics Committee) of

Christian Medical College, Vellore-

Reference No; IRB: 10761

(INTERVEN) 19-07-2017
$>$ Clinical Trials Registry India- Register No: CTRI/2018/05/013888

$>$ Oral and written consent (Informed consent) was obtained from the subjects, prior to data collection.

\section{Results}

Table 3 Effectiveness of Heparinoid Ointment in reducing Phlebitis and Pain between baseline to 24 hours and 48 hours $(n=110)$

\begin{tabular}{|c|c|c|c|c|c|c|c|}
\hline \multicolumn{3}{|c|}{ Time of Observation } & $\mathbf{n}$ & Mean & SD & t value & P value \\
\hline \multirow[t]{4}{*}{ VIP Scale } & \multirow[t]{2}{*}{ Baseline-@24hours } & No change & 42 & \multirow[b]{2}{*}{-0.27} & \multirow[b]{2}{*}{0.53} & \multirow[b]{2}{*}{3.8} & \multirow[b]{2}{*}{$<0.0001 *$} \\
\hline & & Improved & 13 & & & & \\
\hline & \multirow[t]{2}{*}{ @ 48hours } & No change & 0 & \multirow[b]{2}{*}{-1.16} & \multirow[b]{2}{*}{0.42} & \multirow[b]{2}{*}{20.5} & \multirow[b]{2}{*}{$<0.0001 *$} \\
\hline & & Improved & 55 & & & & \\
\hline \multirow{4}{*}{$\begin{array}{ll}\text { Numerical Pain } \\
\text { Intensity }\end{array}$} & \multirow[t]{2}{*}{ Baseline -@24hours } & No change & 32 & \multirow[b]{2}{*}{-0.44} & \multirow[b]{2}{*}{0.54} & \multirow[b]{2}{*}{6.03} & \multirow[b]{2}{*}{$<0.0001 *$} \\
\hline & & Reduced & 23 & & & & \\
\hline & \multirow[t]{2}{*}{ @48hours } & No change & 9 & \multirow[b]{2}{*}{-1.01} & \multirow[b]{2}{*}{0.59} & \multirow[b]{2}{*}{12.7} & \multirow[b]{2}{*}{$<0.0001 *$} \\
\hline & & Reduced & 46 & & & & \\
\hline
\end{tabular}

Table 3 Depicts that at $24^{\text {th }}$ hour observation o 13 subjects showed decrease in VIP score and 42 subjects showed no change with t-value 3.8 (p $<0.0001$ ). At $48^{\text {th }}$ hour reduction in phlebitis is noted in all the subjects. At $24^{\text {th }}$ hour 23 subjects showed reduction in the intensity of pain and 32 subjects showed no change. At $48^{\text {th }}$ hour observation 46 subjects showed reduction in pain with mean t value 12.7 ( $p<0.0001)$.

Table 4 Effectiveness of Glycerine Magnesium Sulphate Paste in reducing Phlebitis and Pain between baseline to 24 hours and 48 hours. $(n=110)$.

\begin{tabular}{|c|c|c|c|c|c|c|c|}
\hline \multicolumn{3}{|c|}{ Time of Observation } & $\mathbf{n}$ & Mean & SD & t value & P value \\
\hline \multirow[t]{4}{*}{ VIP Scale } & \multirow{2}{*}{$\begin{array}{l}\text { Baseline - } \\
\text { @ 24hours }\end{array}$} & No change & 1 & \multirow[b]{2}{*}{-1.56} & \multirow[b]{2}{*}{0.76} & \multirow[b]{2}{*}{15.2} & \multirow[b]{2}{*}{$<0.0001 *$} \\
\hline & & Improved & 54 & & & & \\
\hline & \multirow[t]{2}{*}{ @ 48hours } & No change & 0 & \multirow[b]{2}{*}{-2.52} & \multirow[b]{2}{*}{0.7} & \multirow[b]{2}{*}{25.3} & \multirow[b]{2}{*}{$<0.0001 *$} \\
\hline & & Improved & 55 & & & & \\
\hline \multirow{4}{*}{$\begin{array}{l}\text { Numerical Pain } \\
\text { Intensity }\end{array}$} & \multirow{2}{*}{$\begin{array}{l}\text { Baseline - } \\
@ 24 \text { hours }\end{array}$} & No change & 1 & \multirow[b]{2}{*}{-1.27} & \multirow[b]{2}{*}{0.49} & \multirow[b]{2}{*}{19.3} & \multirow[b]{2}{*}{$<0.0001 *$} \\
\hline & & Reduced & 54 & & & & \\
\hline & \multirow[t]{2}{*}{ @ 48hours } & No change & 0 & \multirow[b]{2}{*}{-1.62} & \multirow[b]{2}{*}{0.56} & \multirow[b]{2}{*}{21.4} & \multirow[b]{2}{*}{$<0.0001 *$} \\
\hline & & Reduced & 55 & & & & \\
\hline
\end{tabular}

Table 4 Depicts that at $24^{\text {th }}$ hour observation 54 subjects showed decrease in VIP score with tvalue 15.2 ( $p<0.0001)$. At $48^{\text {th }}$ hour reduction in phlebitis is noted in all the subjects. At $24^{\text {th }}$ hour
54 subjects showed reduction in the intensity of pain. At $48^{\text {th }}$ hour observation 55 subjects showed reduction in pain with t value $21.4(\mathrm{p}<0.0001)$. 
Table 5: Comparison of effectiveness between Glycerine Magnesium Sulphate and Heparinoid Ointment between baseline to 24 hours. $(n=110)$.

\begin{tabular}{|l|c|c|c|c|c|c|}
\hline Variables & Glycerine Magnesium Sulphate & \multicolumn{2}{c|}{ Heparinoid Ointment } & Test statistic value* & P value \\
\hline & Median & $\begin{array}{c}\left(\mathbf{2 5}^{\text {th }} \text { Percentile, }\right. \\
\mathbf{7 5}^{\text {th }} \text { Percentile) }\end{array}$ & Median & $\begin{array}{c}\left(\mathbf{2 5}^{\text {th }} \text { Percentile, }\right. \\
\left.\mathbf{7 5}^{\text {th }} \text { Percentile }\right)\end{array}$ & & \\
\hline VIP Scale & -1.0 & $(-2.0,-1.0)$ & 0.0 & $(0.00,0.00)$ & 275.0 & $<0.0001^{*}$ \\
\hline $\begin{array}{l}\text { Numerical Pain } \\
\text { Intensity }\end{array}$ & -1.0 & $(-2.0,-1.0)$ & 0.0 & $(-1.0,0.0)$ & 503.0 & $<0.0001^{*}$ \\
\hline * Mann Whitney U test & & & & \\
\hline
\end{tabular}

Table 5: Shows that there is statistically significant difference among the subjects in topical glycerine magnesium sulphate paste group and Heparinoid ointment group at $24^{\text {th }}$ hour observation $(\mathrm{p}<0.0001)$ with median of $-1.0,0.0$ and $25^{\text {th }}$ percentile, $75^{\text {th }}$ percentile of $(-2.0,-1.0)$, $(0.00,0.00), t$ value of $275.0,503.0$ respectively.

Table 6 Comparison of effectiveness between Glycerine Magnesium Sulphate and Heparinoid Ointment from baseline to 48 hours. $(n=110)$

\begin{tabular}{|l|c|c|c|c|c|c|}
\hline Variables & \multicolumn{2}{|c|}{$\begin{array}{c}\text { Glycerine Magnesium Sulphate } \\
\mathbf{n = 5 5}\end{array}$} & \multicolumn{2}{c|}{$\begin{array}{c}\text { Heparinoid Ointment } \\
\mathbf{n = 5 5}\end{array}$} & t value & P value \\
\hline & Mean & SD & Mean & SD & & \\
\hline VIP Scale r Pain & -2.52 & 0.74 & -1.16 & 0.42 & 11.86 & $<0.0001^{*}$ \\
\hline $\begin{array}{l}\text { Numerical } \\
\text { Intensity }\end{array}$ & -1.61 & 0.56 & -1.01 & 0.59 & 5.45 & $<0.0001^{*}$ \\
\hline
\end{tabular}

Table 6 demonstrates that there is a statistically significant difference in phlebitis score among the subjects in glycerine magnesium sulphate paste group and heparinoid ointment group after administration of the intervention and observed at 24 hours and 48 hours $(\mathrm{p}<0.0001)$. VIP score mean of -2.52 , standard deviation of 0.74 and $t$ value 11.86 Numeric pain intensity score mean of -1.16 and standard deviation of 0.42 and $t$ value 5.45 The mean VIP score and mean Numeric pain intensity score is more in glycerine magnesium sulphate paste group as compared with that of heparinoid group. It shows that there is more reduction of VIP score and pain intensity score in glycerine magnesium sulphate paste group.

\section{Discussion:}

The first objective of the study was to assess the effectiveness of Heparinoid (thrombophob) ointment application on reduction in phlebitis.

Table 3 Depicts that that at 24 hours 13 subjects showed decrease in Visual Infusion Phlebitis score and 48 subjects showed no change with standard deviation 0.53 , mean -0.27 and t-value 3.8 (p <0.0001). At 48 hours 46 subjects showed reduction in pain with mean -1.01, standard deviation $0.59, \mathrm{t}$ value 12.7 ( $\mathrm{p}<0.0001)$. At 24 hours 23 subjects showed reduction in the intensity of pain and 32 subjects showed no change. At 48 hours 46 subjects showed reduction in pain with mean -1.01 , standard deviation $0.59, \mathrm{t}$ value 12.7 ( $\mathrm{p}<0.0001)$.

This study was consistent with that of a study conducted on Anti-coagulant ointment in the prevention of post-infusion thrombophlebitis and found that anticoagulant ointment was effective in decreasing the incidence of thrombophlebitis if the duration of infusion was up to 12 hours or less, the use of anticoagulant ointment reduced the average number of days of recovery especially in moderate to severe grades of thrombophlebitis where 169 subjects were included (84 experimental, 85 control)4.At the time of data collection the researcher noticed that three subjects developed allergic reaction after the application of Heparinoid (Thrombophob) ointment among them two are females and one male. Two of them developed allergic reaction within few minutes after the application of the ointment and were excluded from the study the 
other one developed allergic reaction on the $2^{\text {nd }}$ day when the investigator went to observe after 48 hours. They were observed to have symptoms like warmth, redness and itching. The ointment was immediately removed and cold application was done.

The second objective of the study was to assess the effectiveness of Glycerine Magnesium Sulphate paste application on reduction in phlebitis.

Table 4 Depicts that at $24^{\text {th }}$ hour observation 54 subjects showed decrease in VIP score resulting in the reduction of phlebitis with standard deviation 0.76 , mean-1.56, and t-value 15.2 ( $\mathrm{p}<0.0001)$ and 54 subjects showed reduction in the intensity of pain. At $48^{\text {th }}$ hour reduction in phlebitis is noted in all 55 subjects and also showed reduction in pain with mean -1.62 , standard deviation 0.56 , $\mathrm{t}$ value $21.4(\mathrm{p}<0.0001)$.

The findings are consistent with a study conducted to identify the effectiveness of fresh aloe vera and Glycerine Magnesium Sulphate application on phlebitis among children on IV therapy revealed that there was a significant difference in both fresh aloe vera and Glycerine Magnesium Sulphate group on the severity of phlebitis. Magnesium Sulphate paste was found to be the most effective treatment in reducing phlebitis ${ }^{5}$. A quasi-experimental study, findings revealed that Glycerine Magnesium Sulphate dressing is highly effective in decreasing phlebitis on patients ${ }^{10}$. However, there is a lack of scientific evidence on the comparison of the effectiveness of Glycerine Magnesium Sulphate and heparinoid application on phlebitis early and at ease. It was concluded that Glycerine Magnesium Sulphate dressing is highly effective in decreasing phlebitis. based on the observation at 24 hours and 48 hours/

Third objective of the study was to compare the effectiveness of Glycerine Magnesium Sulphate paste and Heparinoid (Thrombophob) ointment.

Table 4 shows the findings regarding the comparison of the effectiveness of the glycerine Magnesium Sulphate and heparinoid application on phlebitis at 24 and 48 hours. The findings indicate that there was a statistically significant difference in the VIP score mean of -2.52 , standard deviation of 0.74 and $t$ value 11.86 and Numeric pain intensity score mean of -1.16 and standard deviation of 0.42 and $t$ value 5.45. The mean VIP score and mean Numeric pain intensity score is more in glycerine magnesium sulphate paste group as compared with that of heparinoid group. It shows that there is more reduction of VIP score and pain intensity score in glycerine magnesium sulphate paste group.

Table 5 shows comparison of the estimated means, in the current study the mean reduction rates in phlebitis is $2.95,2.67$ and 1.78 at baseline, at 24 hours and at 48 hours in the control group and 3.07, 1.51 and 0.55 at the baseline reading, at 24 hours and at 48 hours in the experimental group.

The findings are consistent with the results of the study conducted at Beijing where external application of Magnesium Sulphate paste significantly reduced phlebitis effectively $(p<0.05)^{21}$. The treatment time of phlebitis is reduced by Glycerine Magnesium Sulphate paste application. Hence it clearly explains that the most effective treatment option for phlebitis is Glycerine Magnesium Sulphate paste.

An experimental study done in 2016 revealed that the mean difference of Magnesium Sulphate group (16.62) is higher than the cold application (15.06) and Heparinoid application (15.04) group suggesting that Magnesium Sulphate paste application is most effective in reducing the superficial thrombophlebitis ${ }^{22}$.

\section{Conclusion}

Good clinical practice must be followed starting from the point of reconstituting and drawing up the drug and continue till the administration phase, with special attention paid to the selection of the cannulation sites as regular use of the cannula site increases the risk of infections. Phlebitis is an unpleasant experience which causes pain and discomfort hence requires early 
recognition and prompt intervention. Nurses play a vital role in identification, management and prevention of phlebitis and its complications. If phlebitis is noted in patients then it is best to use the Glycerine Magnesium Sulphate paste application.to treat it. As development of phlebitis affects the overall care more than treatment it is essential to be focused on the preventive aspects. Current study findings demonstrate the evidence on the most effective intervention for the management of phlebitis

\section{Conflict of Interest statement: None \\ Funding Statement: None}

\section{Reference}

1. Alexandrou, E., Ray-Barruel, G., Carr, P. J., Frost, S., Inwood, S., Higgins, N., ... Rickard, C. M. (2015). International prevalence of the use of peripheral intravenous catheters. Journal of Hospital Medicine, 10(8), 530-533.

2. Al, L. P., et. (n.d.). Perception orisk factors for infusion phlebitis among Swedish nurses: a questionnaire study. - PubMed NCBI. Retrieved May 22, 2018, from https://www.ncbi.nlm.nih.gov/pubmed/147 34984

3. Curran, E. T., Coia, J. E., Gilmour, H., McNamee, S., \& Hood, J. (2000). Multicentre research surveillance project to reduce infections/phlebitis associated with peripheral vascular catheters. Journal of Hospital Infection, 46(3), 194-202. https://doi.org/10.1053/jhin.2000.0831

4. Di Nisio, M., Peinemann, F., Porreca, E., \& Rutjes, A. W. (2015). Treatment for superficial infusion thrombophlebitis of the upper extremity. In The Cochrane Library. John Wiley \& Sons, Ltd. https://doi.org/10.1002/14651858.CD0110 15.pub2

5. D'souza, B. L. (2016). Effectiveness Magnesium Sulphate Crystal Fomentation Vs Paste Applicationfor Phlebitis among
Children Receiving Peripheral Infusion who are Admitted at Selected Hospital at Mangalore, 6, 4.

6. Eyk, B. V. (n.d.). Complications of IV Therapy, 10.

7. Gallant, P., \& Schultz, A. A. (2006). Evaluation of a visual infusion phlebitis scale for determining appropriate discontinuation of peripheral intravenous catheters.

8. Huo G, Ying-Jia L, Hui-Juan M.( 2006), Efficacy Observation of Glycerin Magnesium Sulfate Emulsion on the Treatment of Peripheral Phlebitis. Journal of Infusion Nursing; 26: 49-54.

9. Hn, R., \& D, P. K. (2015). A quasi experimental study to evaluate effectiveness of glycerin magnesium sulphate dressing on phlebitis among patients undergoing peripheral intravenous infusion in selected hospital,vadodara. International Journal of Medical Research \& Health Sciences, 4(3), 5-527. https://doi.org/10.5958/23195886.2015.00101.0

10. Ivteam. (12:26:40 UTC). Introduction to the Visual Infusion Phlebitis (VIP) score. Health \& Medicine. Retrieved from https://www.slideshare.net/ivteam/vipscore- introduction

11. Jacinto, A. K. de L., Avelar, A. F. M., Wilson, A. M. M. M., Pedreira, M. da L. G., Jacinto, A. K. de L., Avelar, A. F. M., ... Pedreira, M. da L. G. (2014). Phlebitis associated with peripheral intravenous catheters in children: study of predisposing factors. Escola Anna Nery, 18(2), 220226. https://doi.org/10.5935/1414- 8145 . 20140032

12. Piccini, F., Ragazzoni, G., Valentini, L., Faloia, E., \& Gobbi, P. (2014). Intracellular absorption of transdermal magnesium demonstrated by ESEM-EDS. Italian Journal of Anatomy and 
Embryology, $119(1), \quad 152$. https://doi.org/10.13128/IJAE- 15991

13. Research on Transdermal Magnesium| Tides Wellness. (2018, January 18). Retrieved May 17, 2018, from https://www.thetideswellness.com/researc h-transdermal- magnesium/

14. Saini B, Paul P.( 2011). Effectiveness of cold application, heparinoid application and magnesium sulphate application on superficial thrombophlebitis among pateints. Ind J nsg;2(1):4-10

15. Taylor, F. (2003). A study of the rates of infection and phlebitis associated with peripheral intravenous therapy at the Royal Hobart Hospital. Australian Infection Control, 8(2), 57-60. https://doi.org/10.1071/HI03057

16. Urbanetto, J. de S., Peixoto, C. G., \& May, T. A. (2016). Incidence of phlebitis associated with the use of peripheral IV catheter and following catheter removal. Revista Latino-Americana de Enfermagem, 24. https://doi.org/10.1590/15188345.0604.2746

17. Uslusoy, E., \& Mete, S. (2008). Predisposing factors to phlebitis in patients with peripheral intravenous catheters: A descriptive study. Journal of the American Academy of Nurse Practitioners, 20(4), 172-180. https://doi.org/10.1111/j.17457599.2008.00305.x

18. Xueming J, Yun L. (2005) Correlative study for managing local tissue damage caused by extravasation of pharmorubicin. Journal of Nurses Training; (1): 329.

19. Yambem. (2013). A Comparative Study to Assess the Effectiveness of Glycerin with Magnesium Sulphate Versus Heparin Benzyl Nicotinate (Thrombophob) Ointment on Management of Thrombophlebitis among Patients Admitted in Intensive Care Units (ICU) of
Selected Hospital In Belgaum, Karnataka, 4(7), 4.

20. Zhao Y, Hao Y, Zhang H, Shi J, Xie Y. (2011).Clinical re-evaluation of effects of different treatments to prevent from phlebitis induced by chansu injection. Zhongguo [online] Oct; 36(20):2803-6. Available from: URL: http://www.ncbi.nlm.nih.gov/pubmed/222 92370

21. Zore, G., \& Dias, R. (2012). Effectiveness of Nursing Interventions on Pain Associated with Intramuscular Injection, $3(6), 6$

22. https://www.researchgate.net/deref/http $\% 3$ A\%2F\%2Fdx.doi.org\%2F10.21474\%2FIJ AR01\%2F8213. 